\title{
Dynamics of microcrack propagation in hardwood during heat treatment investigated by synchrotron- based X-ray tomographic microscopy
}

\author{
Marjan Sedighi Gilani • Julie L. Fife • \\ Matthieu N. Boone • Karim Ghazi Wakili
}

Received: 28 August 2012/Published online: 25 April 2013

(C) Springer-Verlag Berlin Heidelberg 2013

\begin{abstract}
The process of crack propagation in wood during pyrolysis is strongly linked to heterogeneities in its hierarchical porous structure. Fundamental understanding of this process is necessary for the analysis of the behavior of wood structural elements during fire exposure. Synchrotron-based X-ray tomographic microscopy combined with a recently developed laser-based furnace at the TOMCAT beamline of the Swiss Light Source provides a unique opportunity to study the heat-induced propagation of microcracks in hardwood in situ with high spatial and temporal resolutions. In this study, attention was focused on the $3 \mathrm{D}$ microstructure of beech and the interconnectivity between morphology and cracking patterns. It is shown that thermal cracks initiate mainly along the ray cells in hardwood and in the junction of seasonal growth layers. There is a clear indication of increased total porosity of the wood due to charring.
\end{abstract}

\section{Introduction}

Despite significant research on timber constructions with regard to fire safety, they are still designed in an oversized manner. This is due to natural variance in physical and mechanical properties of wood and deficient understanding of temperature- and moisture-dependent changes that come from biological origin. Heating reduces the mechanical properties of softwood by thermal softening (Ostman 1985), while the

M. Sedighi Gilani $(\bowtie) \cdot$ K. Ghazi Wakili

Empa, Swiss Federal Laboratories for Materials Science and Technology, Dübendorf, Switzerland e-mail: marjan.gilani@empa.ch

J. L. Fife

Paul Scherrer Institute (PSI), Villigen, Switzerland

M. N. Boone

Department of Physics and Astronomy, Ghent University, Ghent, Belgium 
degree of degradation depends on the temperature and the duration of the exposure. Also, heat drying of softwood leads to shrinkage, development of microcracks in the structure and thus degradation of the overall mechanical properties (Chen et al. 1997). The extent of the crack development is also related to the heating rate (Byrne and Nagel 1997). Shrinkage is not the only reason for crack formation during fire exposure. The ultrastructure of cell walls degrades beyond pyrolysis temperatures by decomposition of the biopolymers and change in the structure of the cellulose microfibrils (Zicherman and Williamson 1981; Brandt et al. 2010). The degradation processes of biopolymers are associated with the formation of fire gases while the component analysis of these gases is a practical measure to predict the charring rate of different wood species (Lingens et al. 2005). Very few studies have been conducted so far on the interrelationship between wood morphology and its behavior during fire exposure. The need to investigate this interrelation at cellular level requires the use of microscopic observations of the process.

X-ray computed tomographic microscopy has proven successful for both descriptive and quantitative characterization of wood and its products at the submicron scale (Rolland du Roscoat et al. 2007; Van den Bulcke et al. 2009; Hass et al. 2010). Furthermore, synchrotron-based X-ray tomographic microscopy enables the visualization and registration of the 3D structure of materials with a high spatial resolution in a matter of minutes (Mannes et al. 2010; Derome et al. 2011). Thus, it is an ideal tool for studying the dynamics of microstructural changes in a material.

In this study, the in situ development of microcracks in hardwood during the charring process is documented in 3D for the first time. Synchrotron-based X-ray tomographic microscopy in combination with a laser-based heating system (Fife et al. 2012) was used to study the dynamics of crack propagation in hardwood in real time. Samples are from beech, a construction material often used in European standards. The change in the 3D structure and porosity at the cellular level was investigated with special attention paid to the location of the development of microcracks during heating to $350{ }^{\circ} \mathrm{C}$ which was achieved at a rate of $1-2{ }^{\circ} \mathrm{C} / \mathrm{sec}$.

\section{Experimental procedure}

Nondestructive synchrotron-based X-ray tomographic microscopy at the TOMCAT beamline of the Swiss Light Source (Stampanoni et al. 2006) was used for in situ studies of the pattern of crack growth in hardwood during heating. Using polychromatic (white-beam) radiation instead of monochromatic radiation from the $2.9 \mathrm{~T}$ superbending magnet at the SLS increased the flux of photons by two orders of magnitude which decreases the time the sample is exposed to the X-rays during image acquisition. The high-speed pco.Dimax CMOS camera reads out the individual projections much faster than traditional CCD cameras, which further decreases the acquisition time of individual projections. The pixel size of the acquired images was 1 micron, while full 3D images were acquired in 6 s. Figure 1 shows the experimental setup, including the furnace, which incorporates two nearinfrared (IR) diode lasers, working at a wavelength of $980 \mathrm{~nm}$ and providing a 


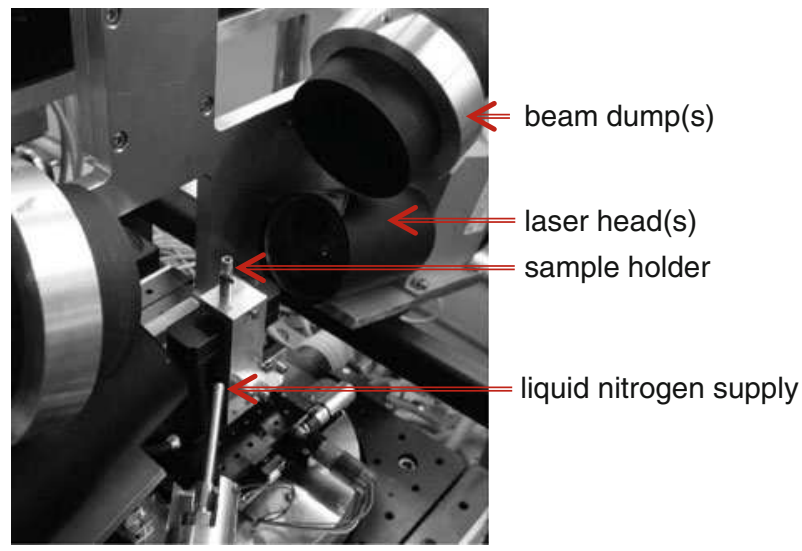

Fig. 1 Laser heating system mounted on the TOMCAT beamline. The sample is fixed in a sample holder of boron nitride ( $5 \mathrm{~mm}$ diameter), installed on a rotating stage. Beam dumps are for absorbing the portion of the beam that does not fall on the specimen

maximum power output of $150 \mathrm{~W}$ (Fife et al. 2012). Each laser has a rectangular spot size of $0.2 \times 1.0 \mathrm{~mm}^{2}$ at working distance of $40 \mathrm{~mm}$. The temperature is read by a pyrometer that is tailored to the emissivity of the sample holder, which in this case is boron nitride. Boron nitride is mostly transparent to X-rays (in the energy range at TOMCAT) and has excellent thermal and chemical stability at temperatures up to $1,500{ }^{\circ} \mathrm{C}$ (Arya and D'Amico 1988).

The wood species studied in this work is beech (Fagus sylvatica), a temperate hardwood species that is often used in European standards because of its durability and treatability properties. The samples of $2 \times 2 \times 2 \mathrm{~mm}^{3}$ were quarter-sawn and dried at $80{ }^{\circ} \mathrm{C}$ prior to the experiments. The sample holder was custom built by engraving a cylinder of $3 \mathrm{~mm}$ diameter and $4 \mathrm{~mm}$ length into a cylinder of $5 \mathrm{~mm}$ diameter. The test sample was placed in the holder with its longitudinal direction parallel to the cylinder axis. After the sample and the lasers were positioned and the heating power was adjusted, tomographic data at the initial state were acquired. Then five tomographic data sets were acquired while the sample was heated to $350{ }^{\circ} \mathrm{C}$ at a rate of $1-2{ }^{\circ} \mathrm{C} / \mathrm{sec}$. Each $3 \mathrm{D}$ tomographic data acquisition took $6 \mathrm{~s}$, dictated by data acquisition system that is fast enough to assume sample in a quasisteady-state condition.

\section{Data processing and analysis}

Coherent X-ray propagation through the sample was used for 3D reconstruction of the images. The simultaneous phase and amplitude retrieval algorithm (Paganin et al. 2002) was used for phase-contrast image reconstructions. Two advantages of this approach are the removal of phase artifacts and the increase in the signal-tonoise ratio (Boone et al. 2012). After reconstruction, each tomographic data set 
consisted of 2016 radial-tangential cross-sectional slices with an isotropic pixel size of $1 \times 1 \times 1 \mathrm{\mu m}^{3}$ in $2 \times 2 \times 2 \mathrm{~mm}^{3}$ field of view, hence $2,016^{3}$ pixels.

Figure 2 shows the three-dimensional structure of beech after rendering a circular crop of 1,200 slices. It clearly shows the vessels of the wood, which are one of the main structural differences between hard- and softwood species. They have different diameters depending on their growth season ranging from 50 to 350 microns and are surrounded by longitudinal cells, called earlywood (springwood) and latewood (summerwood) fibers. Hardwood longitudinal cells (fibers) have a relatively smaller cell diameter and thicker cell walls than the longitudinal cells (tracheids) in softwood. Rays, the horizontal cells passing through the bark to the pith, appear in groups in hardwood and are called multiseriate rays.

Figure 3 illustrates the structure of intact wood (first row) and the locations where microcracks are seen during (middle row) and at the end (bottom row) of the heating experiment. The bold gray area on the left side of the images is due to shrinkage in the sample after heating. Changes in the morphology of microcracks can be observed at these different times. The maximum length of the measured microcracks in the sample is about $350 \mu \mathrm{m}$. One of the main locations where microcracks appear is along the multiseriate ray cells, shown by red, thick arrows (from right to left). In the literature, propagation of cracks in radial direction of softwood has been reported and is considered to be due to development of cracks along the ray tissues that are planes of weakness in timber elements (Walker 1993; Chen et al. 1997). Junction areas between earlywood and latewood zones, as shown by blue, thin arrows (from left to right), are the other morphological feature with a higher concentration of microcracks. Pyrolysis thresholds vary in different chemical components of wood, such as cellulose, hemicelluloses and lignin. As with earlywood and latewood fibers, middle lamella and ray cells consist of different volumetric fractions of these components, and one possible explanation for the observed preferential cracking pattern in wood might be these different thresholds, being a minimum (the most combustible) in cellulose (Zicherman and Williamson 1981).

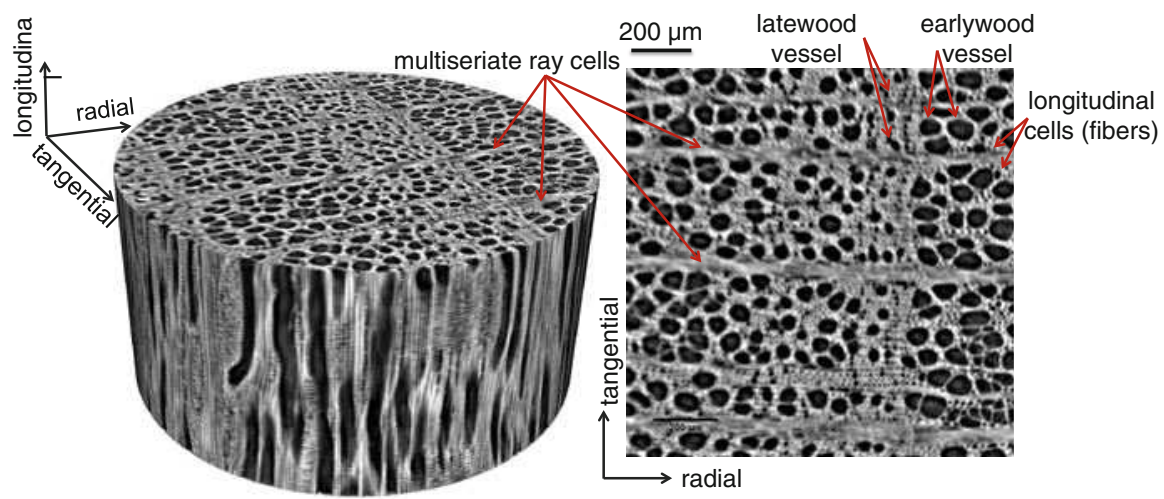

Fig. 2 3D rendering of the reconstructed tomographic microscopy images of a volume of interest in beech wood before heating 


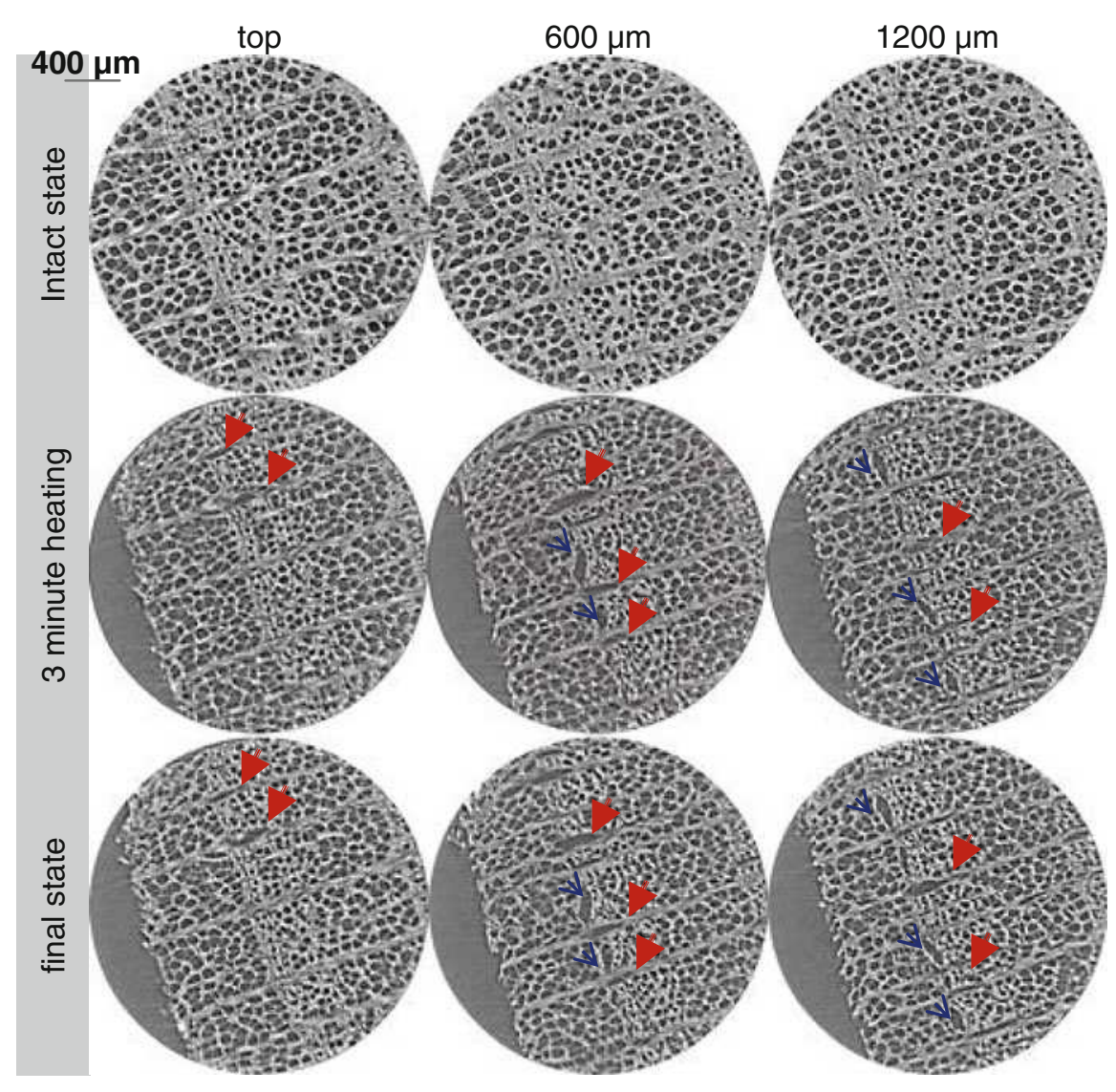

Fig. 3 Cracking morphology is detectable from comparing the sample cross sections at different heights before, during and after heating

Acquired images during the in situ heating experiment are less sharp than when compared to the initial and final images. This is most likely due to movement in the sample, which was instigated by occurring microcracks during the scan and also the formation of fire gases and smoke, which diffuse out and shake the sample while the images are acquired. Although samples had been oven-dried before the experiments and had a minimum amount of hygroscopic water bound in the cell walls, shrinkage of more than $14 \%$ is measured; this most certainly relates to the pyrolysis of material induced by heating.

By segmenting the original tomographic images into binarized data, the observations of Fig. 3 were documented more clearly. For this, gray-level thresholding based on Otsu's method was used, which relies upon a statistical analysis of gray value of image histogram (Otsu 1979). Figure 4 shows the 3D rendered images of the pores, from segmentation of regions of interest (ROI) before and after heating and also their difference over a single slice. ROI in tomographic images of intact and heat-treated wood are selected by comparing specific features 
crack along seasonal growth rings

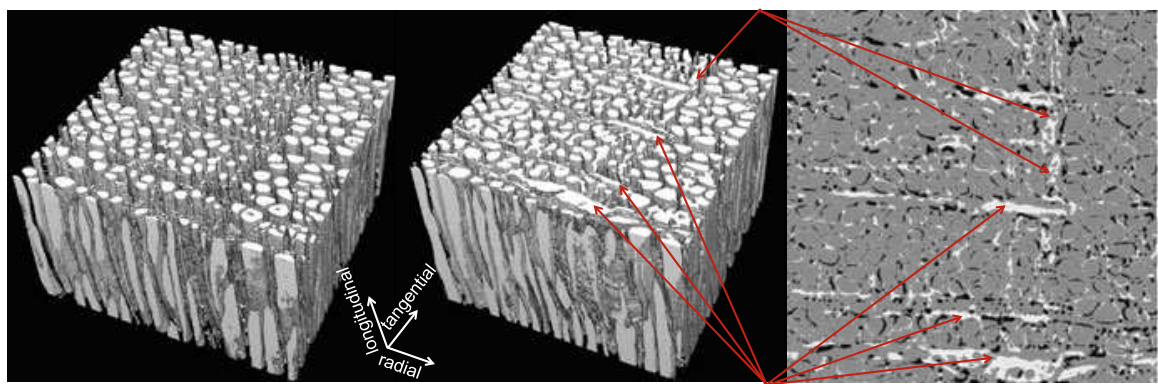

(a)

(b)

(c)

Fig. 4 a 3D pore distribution, mainly earlywood and latewood vessels from rendering the segmented slices of ROI, b vessels plus developed microcracks after combustion, c subtraction of the segmented images of the intact and heat-treated wood highlights the location of microcracks

(landmarks) in each corner of the selected regions in the center of the sample. Comparing Fig. $4 \mathrm{a}$ and $\mathrm{b}$ shows the location of microcracks that extend along the longitudinal direction in the sample. Volumetric fractions of developed microcracks can be determined from evaluating the porosity of the sample before and after heating. Measured porosity of the given ROI for 1,200 slices is about $41 \%$ in intact wood; this changes to about 53 and $55 \%$ in the acquired scans after 3 min and at the end of the heat treatment, respectively. To study the morphology of the developed microcracks, ROI in identical slices, from both before and after heating, are compared by subtraction. As the sample shrinks at different ratios along the radial and tangential directions, this method induces artifacts. To avoid this, affine registered images (Derome et al. 2011) of the heat-treated sample were used. As shown in Fig. 4c, the white color in the resulting image corresponds to the existing solid material in the ROI on the top slice prior to heating, and this area disappears in the heat-treated state. The black regions are generated by the shift of the heat-treated wood with respect to the intact state, which is induced by shrinkage. The location of microcracks is recognized by the large white bundles, confirming they are mainly concentrated along the multiseriated rays and partially in the junction areas between early- and latewood growth layers.

Figure 5 shows the change in gray-level histogram caused by wood heat treatment. The black line corresponds to the histogram of the ROI in intact wood, and the gray line represents the histogram of the same ROI after the heat treatment was complete, both averaged over 1,200 slices. Each histogram possesses two main sections recognized by two peaks. The first section represents the pore fraction, and the second belongs to the solid fraction. Vertical shifts in the histograms of initial and heat-treated wood show the change in the material structure and the pore volume. Pixel intensity in the solid section reduces with heating as a result of the degradation of biopolymers in the cell wall ultrastructure after combustion. Also, heating generates an increase in the peak of the first section of the histogram as a result of development of microcracks and consequently an increase in the pore fraction. 


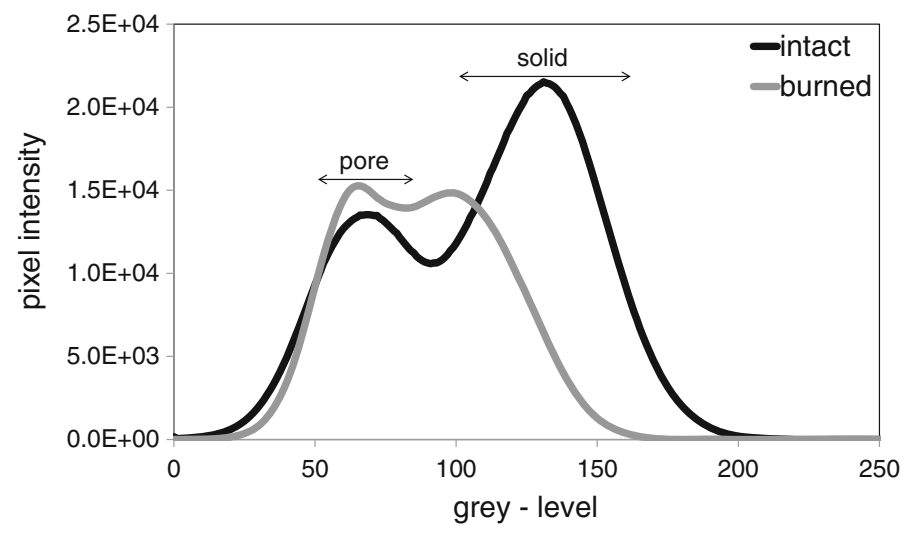

Fig. 5 Gray-level histogram of the sample in the initial state and after combustion shows the change in pore and solid distributions

\section{Conclusion}

Heterogeneity in the morphology of wood, coupled to its chemical composition, induces temperature- and moisture-dependent physical properties that make combustion a difficult process to characterize. Ultrafast X-ray tomographic microscopy coupled with a compact laser-based heating system at the TOMCAT beamline was used to investigate the dynamics of propagation of microcracks in hardwood in real time during combustion. It was shown that the morphology of wood at cellular level plays an important role in its fracture behavior, especially when exposed to high temperatures. Wood shrinks in heat treating, though the volumetric porosity increases due to the development of microcracks. This can be quantitatively studied by comparing the change in pore volume fraction in a representative region of the sample and further be characterized by the change in the histogram before and after heating.

Microcracks initiate first along the multiseriated ray cells, and this is clearly observed within the wood cross-sectional plane. Other critical zones with microcrack concentration are the junction area between the earlywood and the latewood layers.

Acknowledgments The experiment was carried out at the TOMCAT beamline of the Swiss Light Source, Paul Scherrer Institute, Villigen, Switzerland, and we acknowledge it with gratitude. We would also like to acknowledge the support of Dr. Erich Hugi for all discussions, Hannelore Derluyn during the experiments, Stephan Carl for image processing and Rudi Blessing and Erwin Pieper for contribution to sample and sample holder preparations.

\section{References}

Arya SPS, D’Amico A (1988) Preparation, properties and applications of boron nitride thin film. Thin Solid Films 157:267-282

Boone MN, De Witte J, Dierick M, Almeida A, Van Hoorebeke L (2012) Improved signal-to-noise ratio in laboratory-based phase contract tomography. Microsc Microanal 8(2):399-405 
Brandt B, Zollfrank C, Franke O, Fromm J, Göken M, Durst D (2010) Micromechanics and ultrastructure of pyrolysed softwood cell walls. Acta Biomater 6:4345-4351

Byrne CE, Nagel DC (1997) Characterization of wood for advanced materials application. Carbon 35(2):259-266

Chen G, Kee RB, Walker JCF (1997) The drying stress and check development on high-temperature kiln seasoning of sapwood Pinus radiata boards. Holz Roh Werkst 55:59-64

Derome D, Griffa M, Kobel M, Carmeliet J (2011) Hysteretic swelling of wood at cellular scale probed by phase-contrast X-ray tomography. J Struct Biol 173:180-190

Fife JL, Rappaz M, Pistone M, Celcer T, Mikuljan G, Stampanoni M (2012) Development of a laserbased heating system for in situ synchrotron-based X-ray tomographic microscopy. J Synchrotron Radiat 19:352-358

Hass P, Wittel FK, McDonald SA, Marone F, Stampanoni M, Herrmann HJ, Niemz P (2010) Pore space analysis of beech wood: the vessel network. Holzforschung 64:639-644

Lingens A, Windeisen E, Wegener G (2005) Investigating the combustion behaviour of various wood species via their fire gases. Wood Sci Technol 39:49-61

Mannes D, Marone F, Lehmann E, Stampanoni M, Niemz P (2010) Application areas of synchrotron radiation tomographic microscopy for wood research. Wood Sci Technol 44:67-84

Ostman BAL (1985) Wood tensile strength at temperatures and moisture contents simulating fire conditions. Wood Sci Technol 19:103-116

Otsu NA (1979) A threshold selection method from gray-level histograms. IEEE T Syst Man Cyb 9:62-66

Paganin D, Mayo SC, Gureyev TE, Miller PR, Wilkins SW (2002) Simultaneous phase and amplitude extraction from a single defocused image of a homogeneous object. J Microsc 206:33-40

Rolland du Roscoat S, Decain M, Thibault X, Geindreau C, Bloch JF (2007) Estimation of microstructural properties from synchrotron X-ray microtomography and determination of the REV in paper materials. Actamater 55:2841-2850

Stampanoni M, Groso A, Isenegger A, Mikuljan G, Chen Q, Bertrand A, Henein S, Betemps R, Frommherz U, Böhler P, Meister D, Lange M, Abela R (2006) Trends in synchrotron-based tomographic imaging: the SLS experience. Proc. of SPIE 6318:63180M

Van Den Bulcke J, Boone M, Van Acker J, Stevens M, Van Hoorebeke L (2009) X-ray tomography as a tool for detailed anatomical analysis. Ann For Sci 66:508

Walker JCF (1993) Primary wood processing: principles and practices. ChaPman and Hall, London

Zicherman JB, Williamson RB (1981) Microstructure of wood char. Wood Sci Technol 15:237-249 